\title{
3. Opersonlig passiv och opersonliga konstruktioner
}

Detta kapitel tar avstamp i den prototypiska passivkonstruktionen i nederländska respektive svenska vilket utgör utgångspunkten för beskrivningen av opersonliga passivkonstruktioner och andra opersonliga konstruktioner i samma språk.

Svenska har två passivkonstruktioner medan nederländska har en konstruktionstyp för att bilda passiv. I nederländska bildas passiv med hjälpverbet worden 'bli' eller zijn 'vara' kombinerat med ett particip. Detta benämns perifrastiskt passiv. I svenska finns också en perifrastisk passivkonstruktion med hjälpverben bli och vara + particip. Samtidigt har svenska även en morfologisk passivkonstruktion, s.k. s-passiv där ändelsen -s läggs på verbet. Jfr. nederländska i (3.I) med svenska i (3.2) och (3.3).

(3.I) De kinderen worden naar school gebracht.

(3.2) Barnen blir skjutsade till skolan. (bli-passiv)

(3.3) Barnen skjutsas till skolan. (s-passiv)

I många fall är svenskans bli-passiv och s-passiv utbytbara men korpusforskning visar att $s$-passiv förekommer mer frekvent, i fler olika kontexter med olika sorters verb och har blivit den omarkerade passivformen (Engdahl 2006). Det finns emellertid en semantisk skillnad mellan den perifrastiska och den morfologiska passivformen. Bli-passiv anger en avgränsad aktion och fokus ligger i vissa fall på en process som avslutas eller inleds. I satser med $s$-passiv kan aktionen vara oavgränsad och satsen uttrycker inte en dynamisk process (se SAG IV:359-404, 398).

Hur du refererar till det här kapitlet:

Johansson, A. 2019. Kontrastiva studier i nederländska och svenska: Med en inledning om tredjespråksinlärning och tvärspråklig medvetenhet. Pp. 3755. Stockholm: Stockholm University Press. DOI: https://doi.org/Io.I6993/ baz.d License: CC-BY. 
I nederländska finns också en skillnad i betydelse mellan passiv med worden respektive med zijn. Passivkonstrukton med worden bildar passiv i presens och preteritum, se (3.4) och (3.5) medan hjälpverbet zijn används i satser som i svenskan motsvaras av perfekt och pluskvamperfekt, se (3.6) och (3.7).

(3.4a) Wij worden op ijs getrakteerd. (presens)

(3.4b) Vi blir bjudna på glass.

(3.5a) We werden op ijs getrakteerd. (preteritum)

(3.5b) Vi blev bjudna på glass.

(3.6a) Wij zijn op ijs getrakteerd (geworden). (perfekt)

(3.6b) Vi har blivit bjudna på glass.

(3.7a) Wij waren op ijs getrakteerd (geworden). (pluskvamperfekt)

(3.7b) Vi hade blivit bjudna på glass.

I exemplen ovan kan man tolka dem så att passiv med worden uttrycker en process, blir bjudna, medan passiv med zijn - där exempelmeningarna i (3.6) och (3.7) bokstavligen betyder är/var bjudna - är statiskt då hjälpverbet zijn uttrycker ett tillstånd (se Verhagen I992).

\section{Passivkonstruktionens funktion}

Normalt sett är subjektet i en passiv sats objektet i en aktiv sats vilket innebär att en förflyttning av en satsdel har skett. Härigenom skiftar fokus på den information som förmedlas. Man kan även säga att viss information i den passiva satsen hamnar i bakgrunden. Skillnaden mellan aktiva och passiva satser handlar alltså bl.a. om informationsstruktur. Detta illustreras i (3.8) och (3.9). De kinderen/barnen är objekt i den aktiva satsen i (3.8) och subjekt i den passiva satsen i (3.9).

(3.8a) De ouders brengen de kinderen naar school.

(3.8b) Föräldrarna skjutsar barnen till skolan.

(3.9a) De kinderen worden naar school gebracht.

(3.9b) Barnen skjutsas till skolan.

I de passiva satserna i (3.9) ovan har de ouders/föräldrarna utelämnats men de hade kunnat skrivas ut med ett s.k. agentadverbial 
(door de ouders/av föräldrarna). I de aktiva satserna ligger fokus på subjektet ouders/föräldrar och i de passiva satserna har fokus flyttats till kinderen/barnen som är subjekt i dessa handlingar. Man kan sammanfatta det med att fokus har förflyttats från vem som utför handlingen (föräldrarna) till vem som är upplevare/ mottagare av handlingen (barnen). Många gånger skrivs inte agentadverbialet ut för att det inte är viktigt att ange vem som utför handlingen eller för att man inte vet vem det är som utfört handlingen. Det kan även vara underförstått vem som utför handlingen, jfr. (3.IO) och (3.II).

(3.ro) De belastingsaangifte wordt in februari verstuurd.

(3.I I) Deklarationen skickas ut i februari.

I (3.IO) och (3.I I) är det underförstått att det är skattemyndigheten eller motsvarande som skickar ut deklarationen. I (3.I2) och (3.13) är det troligen okänt vem som utfört handlingen eller så vill man inte ange vem som utfört dådet.

(3.I2) De buschaffeur werd in de nacht van 5 mei vermoord.

(3.I3) Busschauffören mördades natten till den 5 maj.

I ovanstående exempel anges alltså inte agentadverbialet men den som utför handlingen förutsätts vara mänsklig, dvs. satserna är agentiva. I (3.I0) och (3.II) kan man förutsätta att det är skattemyndigheten som skickar ut deklarationen vilket innebär att det är en myndighet inte en individ. Här representeras myndigheten av de människor som arbetar där och agentadverbialet, av skattemyndigheten, är därmed agentiv. I (3.I2) och (3.I3) känner man möjligen inte till vem mördaren är men det är en handling utförd av en människa och därmed är satsen agentiv.

\section{Den opersonliga passivkonstruktionen}

Opersonlig passiv är en konstruktion där verbet är passiviserat och subjektet är ett s.k. expletivt subjekt. ${ }^{\mathrm{I}}$ I nederländska används det expletiva subjektet er och i svenska används subjektet det. Detta benämns expletivt er och det när subjektet saknar referens eller betydelse men fungerar som ett led i en sats, jfr. nederländskan i (3.14) och svenskan i (3.15).² 
(3.I4) Er wordt altijd op schoolfeestjes gedanst.

(3.15) Det dansas alltid på skolfester.

Både svenska och nederländska har i princip platshållartvång. Det innebär att ett led måste uppta en plats i den syntaktiska strukturen och i detta fall subjektets plats. För att satserna (3.I4) och (3.I5) ska innehålla ett subjekt används expletivt er och det som är icke-referentiella och betydelsetomma. De fyller således en viktig funktion i språket för att satsen ska bli grammatiskt korrekt. Av denna anledning benämns dessa konstruktioner opersonliga dvs. det finns inget utskrivet mänskligt (animat) subjekt i satsen. Dock bör noteras att det finns undantag från regeln om platshållartvång (se exempelmeningarna (3.27) - (3.29) nedan).

I vanliga passiva konstruktioner, som vi kan kalla prototypisk passiv, har en omflyttning av subjekt och objekt skett där objektet $\mathrm{i}$ en aktiv sats har blivit subjekt $\mathrm{i}$ en passiv sats. Subjektet $\mathrm{i}$ den aktiva satsen kan erhålla funktionen agentadverbial i den passiva satsen. Ibland skrivs agentadverbialet ut men oftast inte (se ovan). I opersonliga passiver sker ingen objektsförflyttning till subjektsposition, istället står objektet kvar och det expletiva er för nederländskan och det expletiva det för svenskan upptar subjektspositionen. Följande mönster åskådliggör omflyttningen av satsdelar från aktiv sats i (3.16) och (3.17) -> prototypisk passiv i (3.18) och (3.19) -> opersonlig passiv i (3.20) och (3.21).

(3.I6) Het bedrijf bouwt nu het nieuwe centraal station.

(3.I7) Företaget bygger nu den nya centralstationen.

(3.I8) Het nieuwe centraal station wordt nu gebouwd.

(3.19) Den nya centralstationen byggs nu/Den nya centralstationen blir byggd nu.

(3.20) Er wordt nu een nieuw centraal station gebouwd (door het bedrijf).

(3.2I) Det byggs nu en ny centralstation (av företaget).

Iovanstående exempel framgår att objektet i de aktiva satserna i (3.I 6) och (3.I7), het nieuwe centraal station/den nya centralstationen, har en objektsliknande funktion i de opersonliga passiva satserna i (3.20) och (3.2I). Skillnaden är dock att objektet i den opersonliga passiva satsen måste stå $\mathrm{i}$ indefinit form een nieuw centraal station/ en ny centralstation. Hur blir det då om det indefinita objektet flyttas 
upp i subjektsposition i prototypisk passiv? Här finns en skillnad mellan nederländska och svenska, jfr. (3.22) och (3.23).

(3.22) *Een nieuw centraalstation wordt gebouwd.

(3.23) En ny centralstation byggs/blir byggd.

I nederländskan krävs ett expletivt er i dessa konstruktioner, annars uppfattas satsen som ogrammatisk, jfr. (3.22) och (3.24)). I svenska anses satsen i (3.23) vara grammatisk beroende på kontext. I nederländsk grammatik kallas konstruktioner som i (3.20) för presenteringskonstruktioner istället för opersonlig passiv eftersom fokus ligger på att presentera ny information. Man kan dock med fog hävda att det är skillnad på presenteringskonstruktioner med worden i (3.24) och på aktiva presenteringskonstruktioner som i (3.25), med till exempel staan, jfr.

(3.24) Er wordt een centraal station gebouwd.

'Det byggs en ny centralstation'

(3.25) Er staan hier nieuwe huizen.

'Det står nya hus här'

Det som utmärker opersonlig passiv till skillnad från aktiva presenteringskonstruktioner är agentiviteten. I opersonliga passiva konstruktioner finns en underförstådd mänsklig agens, dvs. i satsen i (3.24) är det underförstått att byggandet av centralstationen sker med mänsklig hand. Agentadverbialet skulle kunna skrivas ut men det förekommer mindre frekvent och typiskt för opersonlig passiv är att agens ofta är en icke-specifik grupp människor som utför en generell handling. Detta är inte fallet med presenteringskonstruktionerna som saknar s.k. underförstådd mänsklig agens som utför handlingen, se (3.25).

I ovanstående exempelmeningar i (3.24) och (3.25) beskrivs er som s.k. presentatief-er 'presenterings-er' i presenteringskonstruktioner i ANS (I997:467ff). I svensk grammatik kallas det för formellt subjekt i presenteringskonstruktioner och i översättningen i (3.25) är det s.k. egentliga subjektet nya hus i satsen det står nya hus här. Om man jämför med satser som det dansas alltid $p a ̊$ skolfesterler wordt altijd op schoolfeestjes gedanst kan man inte hävda att er och det är formella subjekt eftersom det saknas egentligt subjekt i satserna. Detta hänger också ihop med att satserna 
är intransitiva, dvs. det finns inget objekt i satsen till dansa/dansen (se vidare under avsnittet om transitiva och intransitiva satser).

Nederländskan använder alltid expletivt er när det egentliga subjektet är en indefinit nominalfras oavsett om satsen är aktiv eller passiv. En indefinit nominalfras står således vanligen inte på subjektsplatsen, se (3.26).

$(3.26 a) *$ Nieuwe huizen staan hier.

(3.26b) ?Nya hus står här.

I svenskan förekommer också presenteringskonstruktioner med formellt subjekt det, som i översättningen i (3.25) men en indefinit nominalfras i subjektsposition behöver inte vara ogrammatiskt, jfr. satsen i (3.26b).

Överlag gäller principen att subjektet är obligatoriskt i svenska och nederländska och det kallas subjektstvång (SAG IV:30-3 I och ANS I997:467ff). Svenskans det och nederländskans er fungerar då som platshållare för ett eventuellt egentligt subjekt såsom i (3.25) ovan. Det finns dock undantag i både nederländska och svenska. Ett exempel på detta gäller er och det i vissa konstruktioner med opersonliga passiver. Det expletiva subjektet är då optionellt. I nederländska gäller det när satsen inleds med ett topikaliserat particip, se (3.27).

(3.27a) Verwacht wordt dat de minister spoedig zal aftreden.

*Förväntat blir att ministern snart ska avgå

(3.27b) Det förväntas att ministern snart ska avgå.

Den svenska satsen i $(3.27 \mathrm{~b})$ måste innehålla ett det oavsett topikalisering av participet eller ej. Ett annat exempel på optionellt er är när bisatsen följs av en huvudsats i passiv (se ANS 1997:475), illustrerat i $(3.28) .^{3}$

(3.28a) Omdat zij ver van het ziekenhuis woonde, werd (er) afgesproken dat ze zou bellen.

(3.28b) Eftersom hon bodde långt ifrån mottagningen avtalades (det) att hon skulle ringa.

I (3.28b) är även expletivt det i svenskan optionellt. Optionellt det i svenska är även möjligt i en sats som i (3.29a). 
(3.29a) I skogen sågs (det) vilda djur.

$(3.29 \mathrm{~b})$ In het bos werden (er) wilde dieren gezien.

I SAG (IV:44) anges att det i svenskan är möjligt att uppfatta satser med ett rumsbetecknande adverbial på en plats där annars expletivt subjekt hade kunnat stå som subjektslösa. ${ }^{4}$ Det finns även exempel på detta i nederländska och satsen i (3.29b) har också optionellt er (ANS I997:I4I7ff).

Svenskans opersonliga passiv förekommer i princip endast med morfologisk s-passiv, dvs. i denna konstruktion är perifrastisk och morfologisk passiv inte utbytbara. Engdahl (2006:39) visar att några undantag finns och det gäller satser där ett negativt eller kvantitativt satsled kommer före participet, jfr. (3.30) och (3.3I).

(3.30) *Det blir alltid dansat på skolfester.

(3.3 I) Det blev ingenting/mycket gjort.

Satsen i (3.30) är ogrammatisk och s-passiv är att föredra. De få undantag där opersonlig passiv formas med bli uttrycker i princip antingen bristen på uppnått resultat eller aktivitet men även att betoningen ligger på ett kvantifierbart resultat, till exempel ingenting eller mycket såsom i (3.3 I) (Engdahl \& Laanemets 20I 5:I40, Rawoens, Johansson \& Boons 20I6).

Det är även värt att notera att alla verb med $s$-ändelse i kombination med expletivt det inte är opersonlig passiv utan det kan röra sig om s.k. deponensverb vars funktion inte heller är passivisering. De uttrycker ett aktivt skeende såsom i (3.32)).

(3.32) Det ryktas att presidenten ska komma på besök.

Skillnaden mellan passiviserade verb och deponensverb är att deponensverben oftast saknar en $s$-lös motsvarighet eller att verbet får en annan betydelse i s-lös form vilket inte gäller verb i passiv, jämför följande exempel med deponensverb respektive passiviserade verb.

Deponensverb: synas-syna, andas-*anda, ryktas-rykta, fattasfatta, lyckas-lycka med flera (se till exempel SAG I: $553 \mathrm{ff}$.)

Passiviserade verb: tala-talas, hämta-hämtas, skriva-skrivs, säga-sägs, dansa-dansas 
Vidare saknas en underförstådd mänsklig agens i satser med deponensverb vilket är ett av de viktigaste semantiska särdragen hos opersonlig passiv. Om man tittar närmare på konstruktioner med perceptionsverb såsom det känns, det syns, det hörs finns det en underförstådd deltagare. Dock utför denna deltagare inte handlingen utan deltagaren kan benämnas upplevare (SAG $\mathrm{IV}: 372)$. Av denna anledning faller även perceptionsverb utanför kategorin opersonlig passiv.

\section{Transitiva och intransitiva verb i opersonlig passivkonstruktion}

Distinktionen transitivt och intransitivt anger huruvida verbet kombineras med objekt eller inte. Verb som kombineras med objekt benämns transitiva såsom i födelsedagsbarnet fick presenter och verb som inte kombineras med objekt intransitiva såsom i barnet sover. Vissa verb kan kombineras både med och utan objekt som i satsen vännerna äter middag/vännerna äter snabbt. I följande beskrivning av transitiva och intransitiva verb i opersonlig passiv analyseras hela verbfrasen, inte endast verbets semantik, jfr.

- Det åts mycket tårta -> transitivt

- Det åts mycket -> intransitivt

Satserna ovan är båda två opersonliga passiver. I typologisk forskning har det hävdats att opersonliga passiver endast förekommer tillsammans med intransitiva verb. Bland annat hävdar Comrie (I977) att satser med transitiva verb endast genererar prototypiska passivkonstruktioner med uppflyttning av objektet i den aktiva satsen till subjekt i den passiva satsen.

I tidigare exempel på opersonliga passiver ovan är vissa verb transitiva och andra intransitiva. Transitiva satser som (3.24) och (3.25) har, som nämnts tidigare, i nederländsk grammatik traditionellt beskrivits som presenteringskontruktioner (se ANS I 997:467ff). Här uppfattas centraal station och nieuwe huizen vara egentliga subjekt och er ett s.k. presenterings-er. Skillnaden mellan den aktiva presenteringskonstruktionen i (3.25) och 
konstruktionen i (3.24) är att predikatet i (3.24) är en perifrastisk passivkonstruktion med worden + particip och att det finns en underförstådd mänsklig agens (företaget bygger centralstationen) vilket inte gäller exempelmeningen i (3.25). För svenska anges att både transitiva och intransitiva verb kan förekomma i opersonliga passivkonstruktioner. Dock skulle de transitiva passiverna även i de skandinaviska språken kunna benämnas presenteringskonstruktioner men gör det traditionellt inte utan faller under kategorin opersonlig passiv (Engdahl \& Laanemets 20I5:I32). I SAG nämns fyra konstruktioner med verb i passiv med expletivt det där just en av konstruktionerna har transitivt verb (SAG IV:57). Vidare anges att objektet då är indefinit med vag referens som i $(3 \cdot 33)$.

\section{(3.33) Det spelades kort till långt in på natten. (SAG IV:57)}

Den grammatiska beskrivningen av nederländska och svenska går här isär men mot bakgrund av särdraget underförstådd mänsklig agens skulle man kunna kategorisera den nederländska konstruktionen med transitiva verb som opersonlig passiv. Dock kan de intransitiva konstruktionerna tydligare tolkas som opersonlig passiv än de transitiva konstruktionerna, se (3.34).

$(3 \cdot 34 \mathrm{a})$ Er wordt veel gedanst.

$(3 \cdot 34$ b) Det dansas mycket.

I intransitiva passiva konstruktioner såsom i (3.34) böjs verbet genomgående i 3 :e person singular. Här finns ingen skillnad mellan nederländska och svenska. Skillnad i synsätt beträffande de transitiva konstruktionerna kan förklaras med att fokus inte ligger på verbets böjning vid beskrivningen av opersonliga passiver i svenskan. I svenska syns det inte på verbets kongruens i de transitiva konstruktionerna vilket det egentliga subjektet är i jämförelse med nederländska där verbet kongruerar med det egentliga subjektet i satsen, till exempel er worden huizen gebouwd'det byggs hus' - er wordt een huis gebouwd 'det byggs ett hus'. I svenska förbehålls termen presenteringskonstruktioner endast opersonliga aktiva konstruktioner såsom i (3.35).

(3.35) Det finns/står mjölk i kylskåpet. 
Att detta är en gråzon visar sig i att andra forskare menar att existential-konstruktioner och opersonliga passivkonstruktioner uppvisar stora likheter då båda fyller funktionen att presentera ny information (Carnie \& Harley 2005:47).

Det har noterats att nederländsk och svensk opersonlig passiv förekommer i serier med intransitiva verb och att konstruktionen är produktiv. Dessa konstruktioner fyller en stilistisk funktion och uttrycker ironi eller t. o. m. en raljant ton (Verhagen I992, Viberg 20I0).

(3.36) Er wordt gekankerd, kwaadgesproken, geroddeld en vooral veel geklaagd.

'Det gnälls, baktalas, skvallras och framför allt klagas det mycket'

(3.37) Det söps och urinerades och spyddes och härjades och väsnades rätt bra då också (...).

Man kan i (3.36) och (3.37) se det som att ett scenario målas upp med flera händelser som pågår samtidigt (process) utan att någon enskild individ träder fram ur mängden. Den icke-specifika underförstådda mänskliga agensen kan tolkas så att flera människor utför dessa handlingar inom en bestämd tidsram.

\section{Avgränsad och oavgränsad aktion samt särdraget kontroll}

I det följande diskuteras huruvida aktionen i opersonliga passiver är avgränsad respektive oavgränsad. I forskningen har det visat sig att opersonliga passivkonstruktioner framför allt uttrycker oavgränsad aktion (Carnie \& Harley 2005, Rawoens, Johansson \& Boons 20I6, Johansson \& Rawoens 2019).

(3.38a) Er wordt veel gewandeld.

(3.38b) Det vandras/promeneras mycket.

(3.39a) *Er wordt gevallen.

$(3 \cdot 39 b) *$ Det falls.

I exempelmeningarna i (3.39) är vallen/falla avgränsade och satserna blir därmed ogrammatiska medan wandelen/vandra i (3.38), som är oavgränsade, genererar grammatiskt korrekta satser. Om man tittar på fler element visar det sig att även särdraget kontroll spelar en roll. 
Tabell 3.1. Oavgränsat/avgränsat respektive + kontroll/- kontroll.

\begin{tabular}{lll}
\hline & Oavgränsad aktion & Avgränsad aktion \\
\hline & $\begin{array}{l}\text { Skeenden utan naturlig } \\
\text { slutpunkt }\end{array}$ & $\begin{array}{l}\text { Skeenden med naturlig } \\
\text { slutpunkt }\end{array}$ \\
\hline werken & aankomen/arriveren \\
\hline kontroll & arbeta & anlända/komma \\
\hline kontroll & blöda & sterven \\
\hline
\end{tabular}

Enligt Zaenen (I993) uttrycker den opersonliga passivkonstruktionen oavgränsad aktion och innehåller särdraget + kontroll för att bli grammatisk. Se Tabell 3.I delvis från Zaenen (I993).

I satserna (3.40a) och (3.40c) är satserna aktiva och i (3.4ob) och (3.40d) har de transformerats till passiva satser med expletivt er och det, jfr. exempelmeningarna och Tabell 3.I.

(3.40a) De meisjes hebben hard gewerkt. Flickorna har arbetat hårt.

(3.40b) Er werd hard gewerkt (door de meisjes). Det arbetades hårt (?av flickorna).

(3.40c) De man heeft gebloed. Mannen har blött.

(3.40d) *Er werd gebloed (door de man). *Det blöddes (av mannen).

Den opersonliga passivkonstruktionen i (3.40b) är grammatisk när + kontroll och oavgränsad aktion uttrycks i verbet werken/ arbeta. I (3.40d) är satsen också oavgränsad men verbet bloeden/ blöda bär särdraget - kontroll vilket gör satsen ogrammatisk. Verb såsom stinken/ stinka, ruiken/lukta bildar opersonliga aktiva satser: det luktar/stinker/blöder respektive het ruikt/stinkt/bloedt och fungerar inte i opersonliga passiver.

När en aktiv sats anger såväl avgränsad aktion som - kontroll går den inte heller att transformera till en grammatisk korrekt opersonlig passiv, jfr. de aktiva satserna i (3.4 Ia) med de passiva satserna $\mathrm{i}(3.4 \mathrm{Ib})$. 
(3.4 Ia) In dat ziekenhuis sterven (er) veel patiënten. På det sjukhuset dör (det) många patienter.

(3.4 Ib) *In dat ziekenhuis wordt er (door veel patiënten) gestorven. *På det sjukhuset dös det (av många patienter).

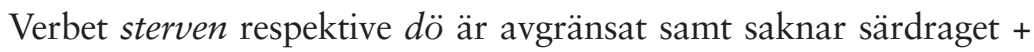
kontroll. Dock kan tilläggas att det i vissa textgenrer kan förekomma opersonliga passiva konstruktioner såsom i skönlitteratur, där satser som avviker från nämnda mönster förekommer, se $(3.42) .5$

(3.42) Er wordt weleens gestorven, maar onopvallend, en omdat het erbij hoort. ${ }^{6}$

'?Det dös av och till men obemärkt och bara för att det hör till'

I nederländska förekommer satser som i (3.42) i vissa textsorter och är nog inte heller omöjliga i svensk skönlitteratur. Den ironiska tonen i exemplet tycks ha samma stilistiska funktion som i exempelmeningarna i $(3.36$ och (3.37) där serier av passiviserade verb förekommer.

Till sist kan nämnas i relation till avgränsad respektive oavgränsad aktion att nederländska har ett tvådelat hjälpverbsystem beträffande perfekt där detta tempus formas med antingen hjälpverbet hebben 'ha' eller zijn 'vara', till exempel zij heeft gewerkt 'hon har arbetat' och hij is begonnen 'Han har börjat'. Satser med hebben tolkas som oavgränsade och satser med zijn tolkas som avgränsade (Klooster 200I:44ff). Verbet sterven 'dö' i (3.42) kombineras med hjälpverbet zijn i perfekt och är därmed avgränsat. Eftersom avgränsade aktioner i princip är inkompatibla med opersonlig passiv blir satser med verbet därför ofta ogrammatiska. Dock ligger ju även den avgränsade aktionen i verbets semantik vilket förklarar varför avgränsade aktioner i princip inte heller är kompatibla med svenska opersonliga passiver som i översättningen i (3.42).

\section{Opersonliga konstruktioner}

Svenska och nederländska har flera konstruktioner som fungerar parallellt med opersonlig passiv, s.k. opersonliga aktiva konstruktioner. Konstruktionerna är inte helt utbytbara utan fyller olika 
funktioner beroende på kontext. Det kan handla om genre eller om idiomatik. En opersonlig passivkonstruktion kan motsvara en aktiv konstruktion där ett opersonligt pronomen används för att uttrycka att agens är icke-specifik och mänsklig. I vissa kontexter kan man byta ut den opersonliga passivkonstruktionen mot nederländskans men respektive svenskans man, jfr. (3.43) med (3.44). ${ }^{7}$

(3.43a) Er wordt druk gevoetbald. (opersonlig passiv)

(3.43b) Det spelas fotboll intensivt.

(3.44a) Men voetbalt druk. (opersonlig aktiv)

(3.44b) Man spelar fotboll intensivt.

Ramat \& Sansò definierar man-konstruktionen i ett flertal europeiska språk som en opersonlig aktiv konstruktion där talaren sätter aktionens agent i bakgrunden (agent-defocusing) antingen för att den är generisk och inte går att identifiera eller för att den är specifik men okänd (2007:96). Man-konstruktionen används bl.a. i konstruktioner där man motsvarar hela mänskligheten (Ramat \& Sansò 2007:I00). Denna generella betydelse illustreras i (3.45).

(3.45a) Men leeft maar één keer. (exempel från Weerman 2006:26).

$(3.45 \mathrm{~b})$ Man lever bara en gång.

Men och man kan dock också vara icke-specifikt och åsyfta en mindre grupp människor, såsom i (3.46).

(3.46a) Men vond haar te jong.

(3.46b) Man tyckte att hon var för ung.

I (3.46b) kan man tala om vag referens (SAG II:395). Vem/vilka som tycker att hon är för ung är outtalat men agensen är mänsklig och samma funktion uppfylls som i passivkonstruktioner där information angående identiteten på dem som uttalar sig inte ges.

På svenska kan man dessutom användas med en mycket specifik referens, nämligen talaren själv, och man kan i dessa fall i allmänhet bytas ut mot jag, jfr. (3.47) och (3.48).

(3.47) Man blir ju ledsen när ingen hör vad man säger.

(3.48) Ik word verdrietig als niemand hoort wat $i k$ zeg. 'Jag blir ledsen om ingen hör vad jag säger' 
I satser som (3.47) är utgångspunkten talarens personliga erfarenhet men samtidigt generaliserar talaren sin erfarenhet till att kunna inbegripa andra människor i samma situation (Pettersson I978:22). I SAG (II:265) tas också denna betydelse upp för svenskan och att betydelsen då ligger nära I:a personens personliga pronomen. I vissa fall finns ytterligare en dimension i detta personliga bruk av svenskans man. Det är även en möjlighet att distansera sig från en emotionell utsaga om sig själv: man mår ju inte bra när sådant här händer. Pettersson (I978:22) beskriver också bruket av man som syftande på talaren själv "en yttring av anspråkslöshet och tillbakadragenhet”, t. ex som svar på påståendet: - vad kunnig du är. - man har väl läst mycket om det genom åren.

Nederländskans men används aldrig som åsyftande talaren själv. Det finns ytterligare restriktioner för användningen av men och det gäller textsort. Men används främst i formellt språk (ANS I997:256; Weerman 2006:3 I) medan svenskans man uppvisar större variation och förkommer frekvent såväl i litterära texter som i sakprosetexter (Altenberg 2005:93). Man förekommer också mycket frekvent i talspråk. Av denna anledning används också man betydligt mer frekvent än men och istället för att använda men i nederländska är obetonat pronomen je 'du' det vanligaste sättet att uttrycka opersonlig icke-specifik betydelse (Weerman 2006; Coussé \& Van der Auwera 20I2). Ett exempel på detta ges i (3.49).

(3.49a) Je kon niet horen dat hij loog.

(3.49b) Man kunde inte höra att han ljög.

Satsen i $(3.49 \mathrm{~b})$ kommer från översättningskorpusen SALT där den svenska satsen i $(3.49 \mathrm{~b})$, med en man-konstruktion, har översatts till nederländskans $j e$ 'du' i (3.49a). Svenskans $d u$ är inte omöjlig i denna sats och enligt SAG (II:264) förefaller bruket av $d u$ bli vanligare i kontexter där man även kan användas. Dock förefaller man-konstruktion eller en konstruktion med deponensverbet höras, såsom i det kunde inte höras att han ljög (jfr. (3.49b)) mer frekvent än pronomen $d u$. Vad gäller nederländskans bruk av je respektive men kan man dra en parallell till engelskans bruk av you respektive one som 
opersonligt pronomen på så vis att you används mer frekvent och one är mer formellt.

Det finns ytterligare opersonliga pronomen som används för att uttrycka att agens är icke-specifik och mänsklig, till exempel någon, ingen, folk osv., som i (3.50).

(3.50) Ingen/någon öppnade.

På nederländska uttrycks satsen i (3.50) dock vanligen med en opersonlig passiv, illustrerat i (3.5 I).

(3.5 ra) Er werd (niet) opengedaan.

$(3.5 \mathrm{Ib}) *$ Det öppnades (inte).

I svenska är opersonlig passiv i $(3.5 \mathrm{Ib})$ ogrammatisk. Givetvis kan indefinita pronomen såsom iemand 'någon' och niemand 'ingen' även användas på nederländska för att uttrycka opersonlig referens men i konstruktionen i (3.5 Ia) förefaller opersonlig passiv mer frekvent. Skillnaden mellan konstruktionerna i (3.5 Ia) och $(3.5 \mathrm{Ib})$ visar att det finns olika sätt att uttrycka opersonlig icke-specifik betydelse i nederländska och svenska.

Ett antal nederländska verb såsom kloppen 'knacka', beuken 'banka/bulta', rammen 'slå (in)', slagen 'slå', aanbellen 'ringa på' förekommer i opersonliga passivkonstruktioner. Dessa verb förekommer i en kontext där en okänd agens knackar, bultar, bankar, ringer på exempelvis en dörr som i (3.52).

(3.52a) Er werd geklopt.

'*Det knackades på dörren'

(3.52b) Det knackar på dörren.

I nederländskan ligger fokus på att en okänd individ utför denna handling eftersom opersonlig passiv uttrycker implicit mänsklig agens. På svenska fungerar opersonlig passivkonstruktion mindre bra i kombination med dessa verb. Istället används främst en opersonlig aktiv konstruktion som i (3.52b) (se Johansson \& Rawoens 20I9). Här ligger fokus främst på det ljud som uppkommer även om satsen givetvis förutsätter att det är en mänsklig agens som utför själva handlingen. Dessa verb benämns av 
Viberg ljudkälleverb (sound emergence verb) (2010:153), jfr $(3.53)$ och (3.54).

(3.53) Er werd hard op de deur gebeukt. “"Det bankades hårt på dörren’

(3.54) Det bankade hårt på dörren.

Skillnaden mellan (3.53) och (3.54) kan förklaras med skillnad i perspektiv mellan nederländska och svenska: i nederländska ligger fokus på en implicit mänsklig agens medan det i svenskan förefaller ligga fokus på det ljud som uppstår genom handlingen med tanke på verbens kategorisering som ljudkälleverb. Vidare skulle detta kunna utgöra en möjlig restriktion för bruket av opersonlig passiv i svenskan. Opersonlig passiv används när en mänsklig agens åsyftas som utgör en icke-specifik grupp av människor. Satsen i (3.54) implicerar att en enda individ utför själva handlingen att banka på dörren. När den implicita agenten är en individ istället för en icke-specifik grupp människor tycks opersonlig aktiv användas (Johansson \& Rawoens 20I9). Ett undantag till detta är svenskans möjlighet att använda opersonlig passiv för att undvika direkt tilltal i ett samtal såsom i betalas det kontant eller ska jag skriva upp det? Här kan man tolka satsen som att endast en person åsyftas. Emellertid har denna typ av konstruktion främst haft som funktion att undvika personligt tilltal med $d u$ eller $n i$.

Svenskans deponensverb utgör också en intressant kontrast med nederländskan. Deponensverb är verb som har $s$-form utan att ha passiv funktion, som nämnts tidigare. De deponensverb som tas upp här är: behövs, hörs, känns, syns och tycks. Dessa verb förekommer i opersonliga konstruktioner där en s.k. generisk upplevare är underförstådd (SAG II:557) vilket gör att konstruktioner såsom det behövs/hörs/känns/syns/tycks påminner om opersonliga passiver. De förefaller dessutom vara starkt lexikaliserade. Det finns ingen entydig motsvarighet till dessa konstruktioner i nederländska men satsen det behövs kan motsvaras av en lexikaliserad fras i nederländska: er is iets nodig, se $(3.55 \mathrm{a})$ och $(3.55 \mathrm{~b})$. 
(3.55a) Er is een microscoop nodig om te kunnen zien hoe hij werkte.

(3.5 5 b) Det behövs mikroskop för att se hur den fungerade.

I en negativ kontext förekommer även det nederländska verbet hoeven 'behöva' där svenskan använder deponenskonstruktionen det behövs, jfr. (3.56a) och (3.56b).

(3.56a) Dat hoeft ook niet.

(3.56b) Det behövs ju inte heller.

Vad gäller svenskans deponenskonstruktion det hörs kan den motsvaras av i princip två olika verb i nederländskan beroende på kontext: klinken i (3.57) och horen i (3.58):

(3.57a) Er klinken heftige stemmen vanuit de keuken.

(3.57b) Det hörs häftiga röster från köket.

(3.58a) Er is niets te horen.

(3.58b) Det hörs ingenting.

Både (3.57) och (3.58) utgör opersonliga aktiva konstruktioner i nederländskan och er is iets/niets te horen 'det hörs någonting/ ingenting' är starkt lexikaliserade. Följande svenska deponensverb följer ett liknande mönster som ovan vad gäller deras motsvarighet på nederländska:

det känns som att (...) - het voelt alsof (...)

det syns på (...) - het is te zien aan (...)

det tycks som mycket länge sedan - het lijkt erg lang geleden

Det kan noteras att nederländskan har både er och het som kan stå på subjektsplatsen. I ANS diskuteras hur mångfacetterad er är beträffande dess funktion i språket. I vissa kontexter kan man beskriva er som adverb och i andra kontexter som pronomen (ANS 1997:464). Het beskrivs som ett indefinit pronomen och kan vara referentiellt och därmed syfta tillbaka på något som nämnts i kontexten eller var aktuellt på något annat sätt (ANS I997:247). Ibland är het icke-referentiellt i satser med exempelvis väderverb: Het regent 'Det regnar' (ANS 1997:258-259). Både het och er kan användas i nederländska opersonliga konstruktioner medan svenskan har det. 


\section{Sammanfattning}

Svenska och nederländska har en uppsättning olika opersonliga konstruktioner. Vissa konstruktioner fungerar på ett liknande sätt hos de två språken, men många gånger finns skillnader i frekvens beroende på textsort och även restriktioner för hur själva konstruktionerna kan användas. Allmänt kan man dessutom säga att nederländsk opersonlig passiv används mer frekvent i jämförelse med svenskans opersonliga passiv vilket två korpusundersökningar har visat (Rawoens, Johansson \& Boons 20I6; Johansson \& Rawoens, 20I9). I den bidirektionella översättningskorpusen SALT (Dut-Swe) har det även visat sig att nederländsk opersonlig passiv i källtexten främst översätts till svenska man-konstruktioner och andra aktiva opersonliga konstruktioner med opersonligt pronomen såsom någon och ingen. De svenska opersonliga passiverna i källtexten i samma korpus översattes i betydligt större utsträckning till nederländska opersonliga passiver i måltexten (Johansson \& Rawoens 20I9).

\section{Noter}

I. I nederländskan benämns denna konstruktion även pseudo-passief då den skiljer sig från den prototypiska passivkonstruktionen (se Kirsner 1976-1977 och Verhagen 1992).

2. Exempel på när det är icke-referentiellt är som subjekt vid satser med väderverb: det snöar. Nederländskan har ytterligare ett pronomen som kan ha icke-referentiell betydelse het vilket förekommer i satser med nederländska väderverb, till exempel het sneeuwt (se ANS I997:258-259).

3. Ibland är er t.o.m. ogrammatiskt i sådana satser.

4. Se även Falk (I993:269ff) beträffande svenska och Grondelaers, Speelman \& Geeraerts (2008) beträffande nederländska.

5. Beliën (20I6) nämner framför allt att de avgränsade verben vallen och sterven kan förekomma i opersonliga passiver trots att de semantiskt sett inte är kompatibla med konstruktionen. 
6. Exemplet kommer från den bidirektionella översättningskorpusen SALT (NL-SVE). Sökbar via https://spraakbanken.gu.se/. Den svenska översättningen lyder: Nog dör det av och till folk, men obemärkt, och bara för att det hör till.

7. Kirsner nämner att det inte alltid går att byta ut en opersonlig passivkonstruktion mot en aktiv men-konstruktion: en nu, Jantje, wordt er geslapen! 'och nu, Jantje, ska här sovas! Jfr. *'en nu, Jantje, slaapt men! ‘?och nu, Jantje, sover man' (I976:398). 